\title{
A Sarcoidosis Patient Presents with Adrenal Insufficiency: A Standardized Patient Scenario for Medical Students and Residents
}

\author{
Shahdi K. Malakooti ${ }^{1}$, Leslie V. Simon ${ }^{2}$ \\ 1. Internal Medicine, Orange Park Medical Center, Orange Park, USA 2. Emergency Medicine/ Medical Simulation, Mayo \\ Clinic, Jacksonville, USA
}

Corresponding author: Shahdi K. Malakooti, smalakootimd@gmail.com

\begin{abstract}
Introduction

The widespread use of corticosteroids for treatment of inflammatory conditions has resulted in the need to promptly recognize drug-induced adrenal insufficiency. This scenario was inspired by an actual case and aims to enhance critical thinking. Our case is unique as we use a case-based format with written tests to track progress.
\end{abstract}

Methods

A pre-assessment was conducted to measure baseline knowledge with residents and medical students. A standardized patient played a 70-year-old female with sarcoidosis who was in the emergency department with weakness and fatigue. The learners obtained her history whereby they discovered that she had recently stopped taking prednisone. They identified adrenal insufficiency and reinstated glucocorticoid therapy. The scenario lasted 10 minutes after which there were a debriefing session and post-debriefing assessment. All were completed in under one hour.

Results

Our pre-scenario assessment revealed that all learners had less knowledge of adrenal insufficiency than thyroid disease with average scores of $66.63 \%$ and $91.25 \%$, respectively. The average score of the adrenal insufficiency test increased from $66.63 \%$ to $87.45 \%$ on the post-debriefing assessment and the largest improvement was seen in first-year residents. Assessments measured via the Likert scale determined that all learners found the case well-devised to contribute to their understanding of adrenal insufficiency.

Discussion

Received 03/12/2018

Review began 06/10/2018 Review ended 06/12/2018 Published 06/18/2018

๑) Copyright 2018

Malakooti et al. This is an open access article distributed under the terms of the Creative Commons Attribution License CC-BY 3.0., which permits unrestricted use, distribution, and reproduction in any medium, provided the original author and source are credited.
The largest improvement unexpectedly was seen in first-year residents which may be due to variations in repetition and retention of medical knowledge in the months prior to starting residency. This module is best suited for first-year internal medicine, family medicine, and emergency medicine residents and upper-level medical students.

Categories: Endocrinology/Diabetes/Metabolism, Emergency Medicine, Rheumatology

Keywords: standardized patient scenario, adrenal crisis, adrenal insufficiency, case-based learning, sarcoidosis, corticosteroids

\section{Introduction}

Adrenal insufficiency is an endocrine disorder in which one or more of the hormones that are normally secreted by the adrenal gland (i.e., aldosterone, cortisol, dehydroepiandrosterone, epinephrine, norepinephrine) are not produced in adequate amounts [1]. Adrenal insufficiency can be categorized as primary, secondary, and tertiary depending on the origin of the disease [1].

The hypothalamus secretes corticotropin-releasing hormone (CRH) which stimulates the anterior pituitary to release adrenocorticotropic hormone (ACTH). ACTH then prompts the adrenal cortex to secrete cortisol. Cortisol itself self-regulates the axis via negative feedback to the hypothalamus and anterior pituitary to maintain cortisol levels in certain ranges throughout the day and in times of stress [2].

Primary adrenal insufficiency occurs due to adrenal gland dysfunction while secondary adrenal insufficiency is a result of anterior pituitary dysfunction [2]. Tertiary adrenal insufficiency, on the other hand, occurs due to hypothalamic dysfunction. Secondary and tertiary adrenal insufficiency are commonly drug-induced, 
whereby exogenous corticosteroids suppress the normal physiologic function of the hypothalamus and anterior pituitary in regulating cortisol levels [2]. This is an important physiologic process to understand because of the widespread use of steroids for a variety of autoimmune and inflammatory diseases.

Prednisone is an example of a corticosteroid commonly prescribed for its immunosuppressant properties and acts analogously to cortisol to suppress the hypothalamic-pituitary-adrenal axis [1]. During times of physiologic stress, the body responds with inflammatory cytokines and molecules that stimulate secretion of cortisol via numerous complex pathways [3]. Cortisol, in turn, reflexively stimulates gluconeogenesis to ensure adequate energy supplies, regulates ion transport, and works to maintain physiologic equilibrium [4]. If $\mathrm{CRH}$ and ACTH are suppressed, then discontinuation of prednisone may result in adrenal insufficiency and in times of physiologic stress may precipitate a life-threatening adrenal crisis (acute adrenal insufficiency) $[5]$.

Drug-induced adrenal insufficiency can be difficult to diagnose since symptoms mimic other conditions and patients may fail to mention which medications they have been taking unless a full history is elicited by the clinician. In drug-induced acute adrenal insufficiency, the constellation of symptoms includes confusion, fatigue, weakness, nausea, abdominal pain, and dizziness from postural hypotension. These findings, as well as laboratory values showing hyponatremia, hypoglycemia, and pre-renal failure, should prompt the clinician to consider secondary or drug-induced adrenal crisis [5]. Primary adrenal insufficiency has similar findings but also includes hyperpigmentation from increased CRH and hyperkalemia due to superimposed mineralocorticoid deficiency [1].

Clinicians should not wait for laboratory results of cortisol levels to treat adrenal crisis due to its severity and the grave implications of delaying administration of steroids. Treatment of adrenal crisis involves large doses of intravenous (IV) or intramuscular (IM) doses of hydrocortisone, as well as rapid rehydration with approximately four to six liters of isotonic saline while frequently observing for signs of fluid overload [5]. Recommended doses of steroid therapy include $100 \mathrm{mg}$ of hydrocortisone IV or IM as a bolus dose, followed by continuous IV administration of $200 \mathrm{mg}$ of hydrocortisone over a period of 24 hours [5]. An alternate method includes pulse dosing of $50 \mathrm{mg}$ of hydrocortisone IV or IM every six hours [5].

The use of a simulated clinical scenario is a valuable tool in the medical armamentarium whereby learners improve analytical and processing gaps in medical decision-making and diagnostic accuracy [6]. Our case was inspired by an actual patient experience, and the simulation was originally implemented as a neurosarcoidosis scenario. Due to its natural complexity, however, very few residents were able to identify neurosarcoidosis and were stumped as to its diagnosis and treatment. We changed the focus to adrenal insufficiency to create a more effective teaching tool and implemented a new standardized scenario.

It is interesting to note that we incidentally found a simulation module published in MedEd from 2015 in which a patient with sarcoidosis presented with adrenal crisis [7]. This leads us to consider that the presentation of adrenal insufficiency in sarcoidosis may have a higher incidence than originally thought. We have created this module to be an integral part of strengthening and solidifying understanding of adrenal insufficiency in the clinical setting. Our case is unique as we can track residents and medical students' understanding of adrenal insufficiency with objective tests. With respect to the educational format of the module, our simulation is in an enhanced simulation format with comprehensive and thorough simulation components.

This is a formative activity designed to enhance these cognitive processes, as well as the ability to diagnose and treat adrenal insufficiency. Our case format is useful for first-year internal medicine, family medicine, and emergency medicine residents, as well as upper-level medical students, to improve clinical knowledge and enhance cognitive capabilities.

\section{Materials And Methods}

This scenario was conducted during noon conference for four internal medicine residents and two upperlevel medical students. Due to the limitations of being in a community hospital, senior internal medicine residents familiar with standardized patient scenarios were recruited to play the roles of the patient and nurse. Prior to the scenario, Dr. Malakooti coached the resident actors and underwent a thorough review of the supplemental materials with them, including the standardized case development tool (Table 1), scenario introduction (Table 2), a note from the husband (Table 3), and a standardized patient scenario (Table 4). Prior to the start of the scenario, a pre-simulation questionnaire was distributed to the residents for selfassessment of their comfort with (and knowledge of) adrenal insufficiency and associated topics (Table 5).

\section{Standardized




\title{
Cureus
}

\author{
Patient name Abigail Kingsley \\ Chief \\ complaint Weakness and fatigue for one week \\ Type and \\ level of \\ Residents and upper-level medical students. \\ learner \\ Case \\ objectives \\ Immediately address and treat acute symptoms of hypoglycemia and hypotension \\ Identify signs and symptoms of adrenal insufficiency \\ Obtain history of presenting illness, medical history, and full pharmacologic history \\ Diagnose drug-induced adrenal crisis \\ Treat adrenal crisis with appropriate steroids \\ Recognize adrenal insufficiency and adrenal crisis along with differential diagnoses \\ Setting \\ Emergency Department
}

Patient profile

Age

70 years old

Religious

background

Baptist

Sex

Female

Sexual

orientation

Heterosexual

Patient

appearance

Well nourished and in clean casual clothing

Physical

limitations

none

Affect Pleasant but sleepy and at times becomes confused

Social

Lives with her husband of 30 years who is very supportive and takes care of her. He actually knows her medications even better than she does.

Education Bachelor of Arts degree

Health literacy Average health literacy

Employment Previously a stay at home mother

Dwelling Owns a one story house

Habits She eats grilled chicken, fish, and vegetables often. She goes on long walks with friends. She does not smoke, drink alcohol, or use illicit substances.

She usually wakes up in the morning and makes eggs and potatoes for her husband and herself, then does some

Daily routine errands until lunchtime. She sees her daughters and their families in the afternoons and evenings and usually has dinner with them.

Case

information

Chief concern

I'm just feeling so tired and weak. I guess I'm just not myself so my husband wanted me to come in and get checked out.

The patient's started or what happened. I just feel so sleepy. My husband says I have gotten a little more forgetful this week. We story just went on a family vacation to Switzerland where my brother-in-law is working at a huge science facility. I've never seen anything like it. It was so beautiful and nice to be with all of our family I just miss everyone so much. 


\section{Cureus}

I ran out of prednisone while we were on our vacation. I haven't had a chance to refill it yet but I will as soon as I get out of the hospital. My doctor prescribed it for me because I have sarcoidosis.

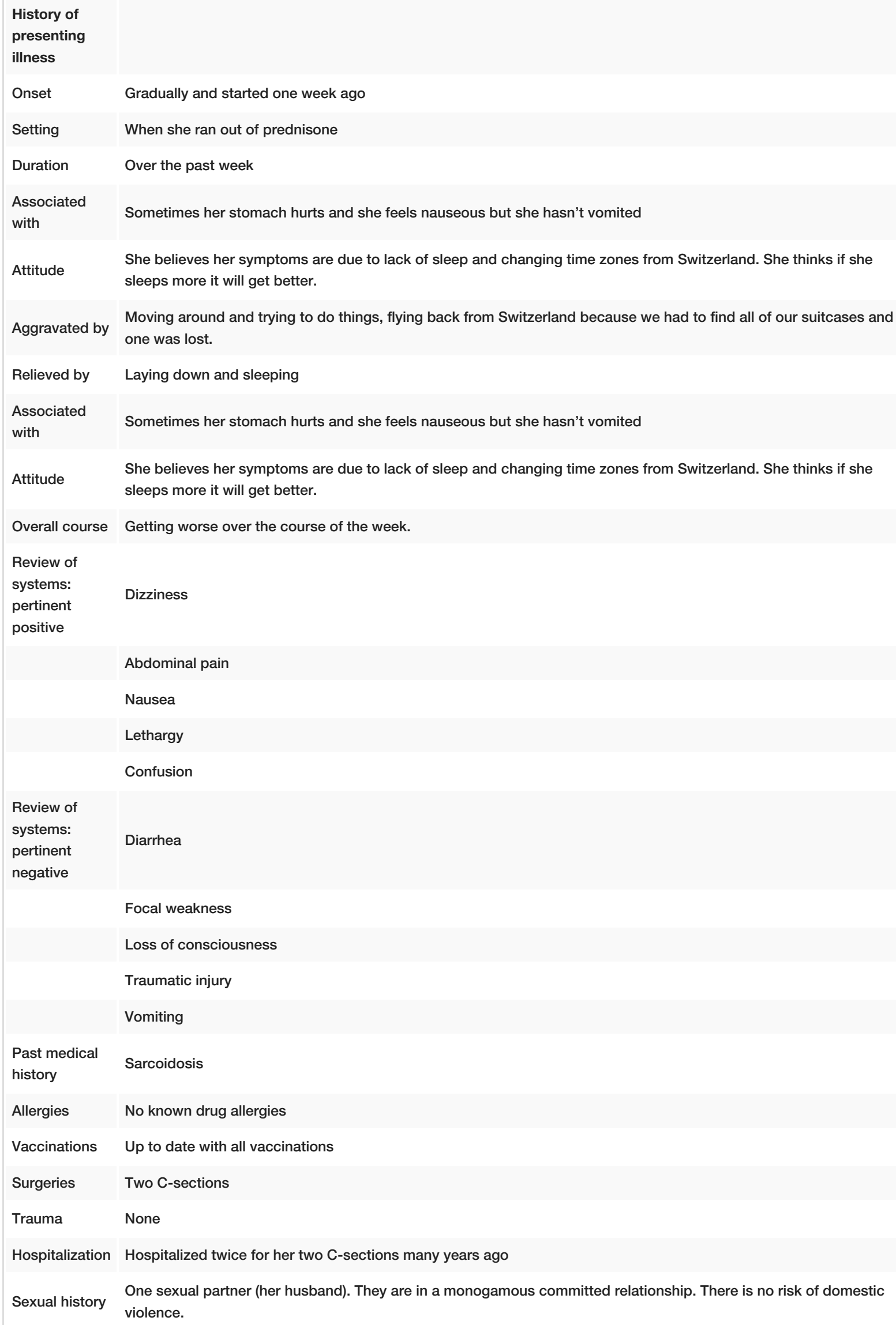
violence. 


\section{Cureus}

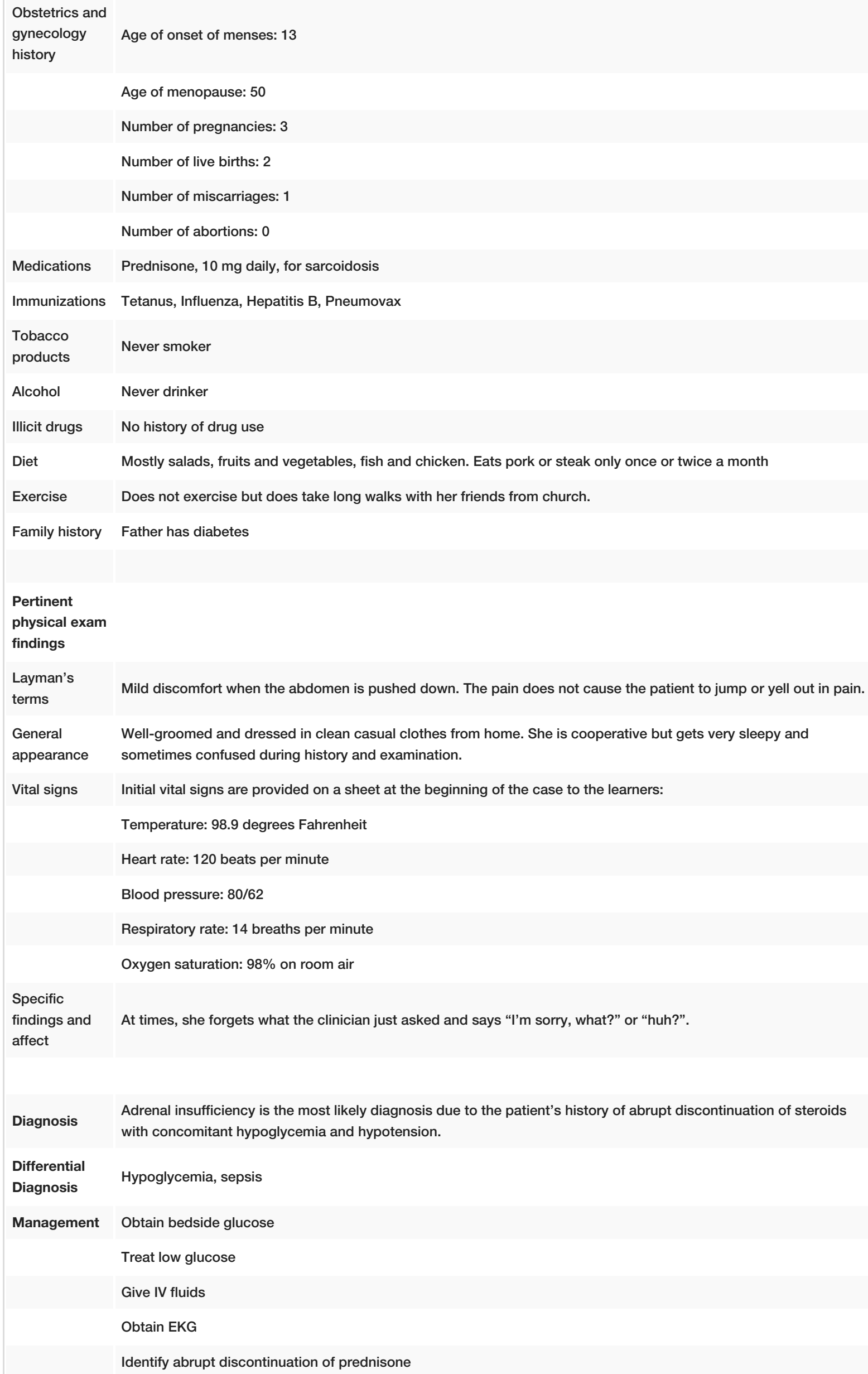




\section{Cureus}

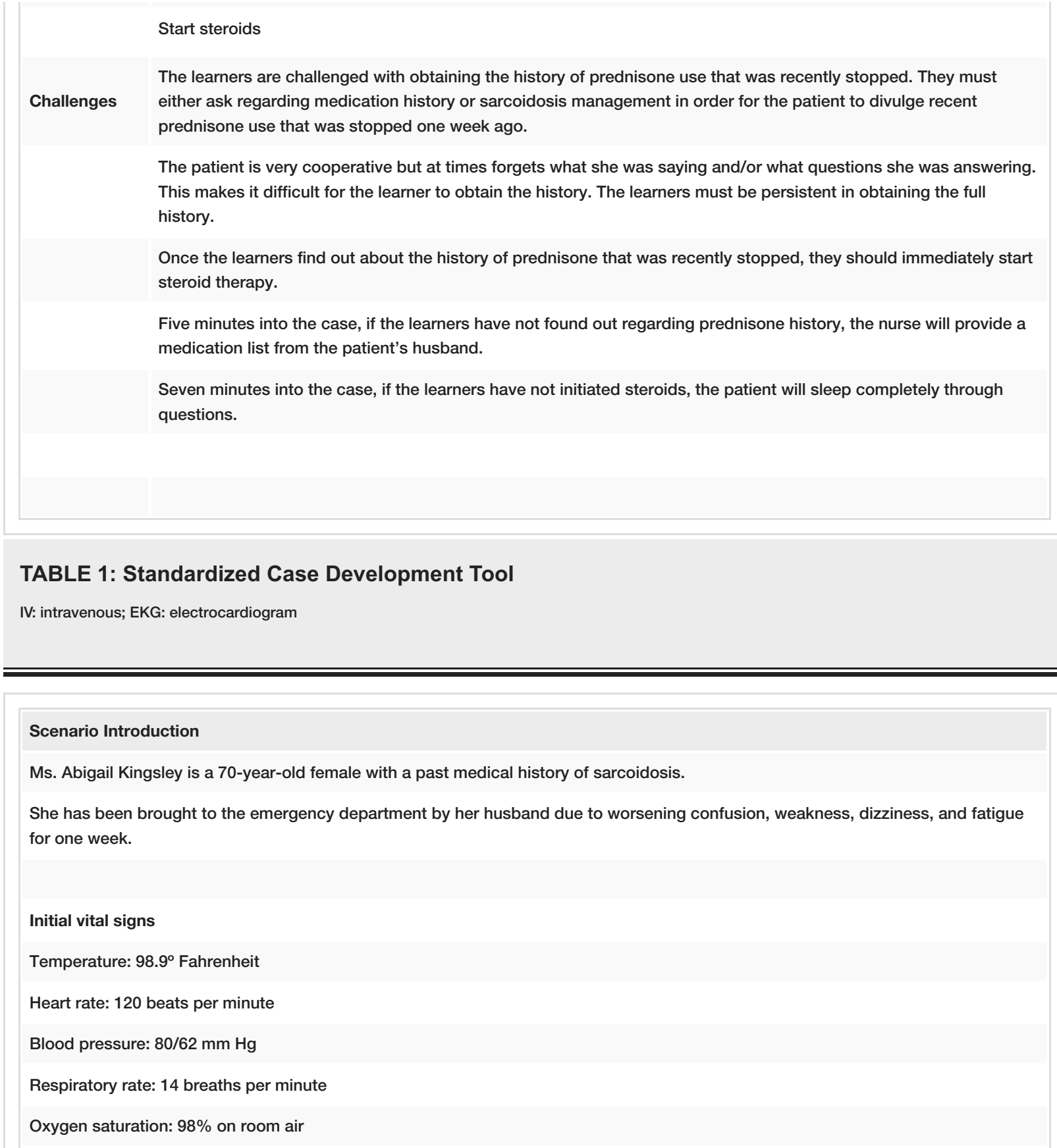

TABLE 2: Scenario Introduction 


\section{Cureus}

Note from husband

Abby's med list:

Prednisone, $10 \mathrm{mg}$ every day (for the past five years)

She forgot to take her pills while we were on our family vacation last week but otherwise she takes it every day. Please help her get better. Thanks doc.

-Richard (Husband) Cell 555-6304

\section{TABLE 3: Note From Husband}

\begin{tabular}{|c|c|}
\hline \multicolumn{2}{|c|}{$\begin{array}{l}\text { A Sarcoidosis Patient Presents With Adrenal Insufficiency: A } \\
\text { Standardized Patient Scenario for Medical Students and } \\
\text { Residents }\end{array}$} \\
\hline Patient Name & Abigail Kingsley \\
\hline Patient Age & 70 years old \\
\hline Chief Complaint & $\begin{array}{l}\text { Confusion, weakness, dizziness, and } \\
\text { fatigue for one week }\end{array}$ \\
\hline \multirow[t]{6}{*}{$\begin{array}{l}\text { Primary Learning } \\
\text { Objectives }\end{array}$} & $\begin{array}{l}\text { Immediately address and treat acute } \\
\text { symptoms of hypoglycemia and } \\
\text { hypotension }\end{array}$ \\
\hline & $\begin{array}{l}\text { Identify signs and symptoms of adrenal } \\
\text { insufficiency }\end{array}$ \\
\hline & $\begin{array}{l}\text { Obtain history of presenting illness, } \\
\text { medical history, and full pharmacologic } \\
\text { history }\end{array}$ \\
\hline & Diagnose drug-induced adrenal crisis \\
\hline & $\begin{array}{l}\text { Treat adrenal crisis with appropriate } \\
\text { steroids }\end{array}$ \\
\hline & $\begin{array}{l}\text { Recognize adrenal insufficiency and } \\
\text { adrenal crisis along with differential } \\
\text { diagnoses }\end{array}$ \\
\hline
\end{tabular}

Critical Actions

Obtain bedside glucose

Treat hypoglycemia intravenously (IV)

Address hypotension with IV fluids

Obtain EKG

Request urine analysis

Request blood cultures

Identify any changes in medication

history

Diagnose drug-induced adrenal crisis

Initiate pharmacologic therapy with appropriate glucocorticoid therapy 


\section{Cureus}

Learner Preparation

A 70-year-old female with a past medical history of sarcoidosis presents with confusion, weakness,

Initial presentation dizziness, and fatigue for the past one week. Initially, unbeknownst to the learner, she suddenly stopped taking her chronic prednisone therapy a week prior to presentation. The learner objectives are to identify adrenal crisis and initiate appropriate pharmacologic treatment prior to progression of adrenal crisis.

Initial vital signs

Temperature: $98.9^{\circ}$ Fahrenheit

Heart rate: 120 beats per minute

Blood pressure: 80/62

Respiratory rate: 14 breaths per minute

Oxygen saturation: $98 \%$ on room air

Overall Appearance

Patient is lying down in a hospital bed. She is lethargic and falls asleep intermittently. She is in no distress.

Standardized patient and At the beginning of the case, an actress plays the role of the patient lying down in the hospital bed. An other roles actor/actress plays the role of the nurse.

History of Presenting The learners must elicit the patient's pharmacologic history of chronic prednisone therapy. The

Illness prednisone was suddenly stopped a week prior as she forgot to take her pills with her while traveling for a family vacation.

Past Medical History

\section{Sarcoidosis}

Past Surgical History

$2 \mathrm{C}$-sections over 30 years ago.

Home Medications

Prednisone, $10 \mathrm{mg}$ by mouth daily, for five years

\section{Allergies}

No known drug allergies

Family history

Father had diabetes

Physical Examination

\section{General}

Head, eyes, ears, nose, throat

Neck

Lungs

Cardiovascular

Abdomen

Neurological

Skin

Genitourinary

Psychiatric

Instructor Notes -

change in case and
Laying in the hospital bed. Appears weak and lethargic

Normocephalic and atraumatic. Pupils are equally reactive to light and accommodation

No abnormal findings

Normal breath sounds

Tachycardia with regular rhythm and no murmur

Mild abdominal tenderness which is diffuse in all quadrants and there is no rebound or guarding

Awake and oriented and no focal neurologic deficits

No lesions

No bladder distension

Cooperative but falls asleep intermittently during history and examination. At times forgets what the clinician is asking and repeatedly says "Huh?" 


\section{Cureus}

branch points

Intervention and time point instructions

Learners obtain serum glucose

Learners treat hypoglycemia with IV dextrose

Learners address hypotension with IV fluids

Learners obtain EKG

Learners obtain urinalysis and request blood cultures

\section{Learners elicit past} pharmacologic history revealing chronic prednisone use that was recently stopped due to traveling for a family vacation

Five minutes after the start of case

Seven minutes after the start of case

Learners treat patient with appropriate IV steroid therapy.

Ideal Scenario Flow

Anticipated Mistakes
Change in Case

Additional information

No change

If IV dextrose therapy is not initiated at three minutes, the patient begins to mumble incoherently.

No change in patient's mental status. Blood pressure improves to 89/64.

EKG image is shown to learners which reveals sinus tachycardia

Results are given to learners which show negative results.

No change

If medical history has not yet been obtained, nurse should enter the room

If no steroids are initiated, patient sleeps through questions.

Patient begins to talk and states she feels much better and is ready to go home. Case ends.
The nurse hands the learners a medication list provided by the patient's husband

The nurse tells the learners that the patient's blood pressure is now $70 / 40$ and asks the learners if they would like to start any treatment for the patient.
Learners enter the hospital room where the patient is lying in bed. They elicit history from the patient which reveals a five-year history of prednisone therapy for sarcoidosis which was abruptly stopped last week as she forgot to take her pills while traveling for a family vacation. The learners treat the patient's immediate symptoms and obtain appropriate initial tests for a hypotensive and hypoglycemic patient. The learners diagnose adrenal crisis and after treatment, the patient becomes alert, awake, and oriented and states that she feels much better.

Failure to obtain bedside glucose and/or treat with IV dextrose

Failure to address hypotension with IV fluids

Failure to obtain EKG to exclude cardiac abnormality including myocardial infarction

Failure to test for infection with urinalysis and blood cultures

Failure to obtain medication history indicating recent medication change: nurse may provide document left behind by the patient's husband

Failure to treat with appropriate steroid therapy: nurse may prompt questioning regarding additional medications for treatment 


\section{Cureus}

\section{TABLE 4: Standardized Patient Scenario}

EKG: electrocardiogram; C-sections: caesarean sections

\section{PRE-SIMULATION QUESTIONNAIRE}

Instructor:

Date:

Which of the following best describes your training level? (please circle)

If you are at the postgraduate level, what is your specialty?

Have you ever participated in a simulation case before?

Please rate your own knowledge and comprehension

of the following topics:

Thyroid storm

Diabetic Ketoacidosis

Myocardial Infarction

Adrenal Insufficiency

Pulmonary Embolism

Sarcoidosis
MS-III

Emergency

Medicine

Yes

1 = very poor

$2=$ poor

$3=$ neutral

4 = good

5 = very good

1

1

1

1

1

1
2

2

2

2
No
PGY-

4 or Fellow

Which of the following best describes the levels in the following conditions? (please circle)

$\begin{array}{llll} & \begin{array}{l}\text { Primary Adrenal } \\ \text { Insufficiency }\end{array} & \text { Tertiary (Drug-Induced) Adrenal Insufficiency } \\ \begin{array}{ll}\text { Cortisol } \\ \text { Low / Normal / } \\ \text { High }\end{array} & \text { Low / Normal / High } \\ \begin{array}{lll}\text { Cortisol } 30 \text { minutes after cosyntropin stimulation } \\ \text { Aldosterone }\end{array} & \begin{array}{l}\text { Low / Normal / } \\ \text { High }\end{array} & \text { Low / Normal / High } \\ & \begin{array}{l}\text { Low / Normal / } \\ \text { High }\end{array} & \text { Low / Normal / High } \\ \text { ACTH } & \text { Low / Normal / } & \text { Low / Normal / High } \\ & \text { High } & \end{array}$

Which of the following best describes the levels in the following conditions? (please circle) 


\section{Cureus}

\begin{tabular}{|llll} 
& $\begin{array}{l}\text { Subclinical } \\
\text { Hypothyroidism }\end{array}$ & Hypothyroidism & Hyperthyroidism \\
Serum TSH & $\begin{array}{l}\text { Low / Normal / } \\
\text { High }\end{array}$ & $\begin{array}{l}\text { Low / Normal / } \\
\text { High } \\
\text { Low / Normal / } \\
\text { Lerum Free T4 }\end{array}$ & $\begin{array}{l}\text { Low / Normal / } \\
\text { High }\end{array}$ \\
Serum Free T3 & Low / Normal / & Low / Normal / High \\
High & High & Low / Normal / High
\end{tabular}

POST-DEBRIEFING / POST- SIMULATION

\section{QUESTIONNAIRE}

Please rate your own knowledge and comprehension of the following topics:

$1=$

poor 2

neutral $^{3=}$

good $4=$

$5=$ very

Adrenal Insufficiency

1

Sarcoidosis

1

2

3

2

5

5

Please answer the following questions regarding the patient scenario.

The simulation case represented a real-life scenario.

strongly disagree

disagree

neutral

agree

strongly agree

The simulation case was well devised to achieve the goals in the debriefing session.

strongly disagree

disagree

neutral

agree

strongly agree

The simulation case contributed to or solidified my

understanding of important concepts.

strongly disagree

disagree

neutral

agree

strongly agree

Which of the following best describes the levels in the following conditions? (please circle)

\begin{tabular}{|c|c|c|}
\hline & $\begin{array}{l}\text { Primary Adrenal } \\
\text { Insufficiency }\end{array}$ & Tertiary (Drug-Induced) Adrenal Insufficiency \\
\hline Cortisol & $\begin{array}{l}\text { Low / Normal / } \\
\text { High }\end{array}$ & Low /Normal/High \\
\hline $\begin{array}{l}\text { Cortisol } 30 \text { minutes after cosyntropin stimulation } \\
\text { test }\end{array}$ & $\begin{array}{l}\text { Low / Normal / } \\
\text { High }\end{array}$ & Low /Normal/High \\
\hline Aldosterone & $\begin{array}{l}\text { Low / Normal / } \\
\text { High }\end{array}$ & Low /Normal/High \\
\hline АСТН & $\begin{array}{l}\text { Low / Normal / } \\
\text { High }\end{array}$ & Low / Normal / High \\
\hline $\begin{array}{l}\text { Please comment here if you have any suggestions } 0 \\
\text { experience: }\end{array}$ & $w$ to make this a m & effective learning \\
\hline
\end{tabular}

\section{TABLE 5: Pre-scenario and Post-scenario Assessments}

MS: medical student; PGY: post-graduate year; TSH: thyroid stimulating hormone; T3: triiodothyronine; T4: thyroxine; ACTH: adrenocorticotropic hormone

The environment was modeled after an emergency room. The patient was found lying down in a hospital bed or stretcher. A blood pressure cuff, heart rate monitor, and oxygen saturation monitor were present, along with an IV pole and simulation bottles of various intravenous medications, including hydrocortisone. A 


\section{Cureus}

document with an introduction to the scenario was provided to the learners which included the patient's chief complaint and initial vital signs (Table 2). Lab values were provided on request (Table 6). A

supplemental document containing a note from the patient's husband would be presented to the learners at the fifth minute of the scenario if they had not yet discovered the patient's past history of long-term prednisone therapy (Table 3). The patient scenario is described in further detail in Table 4 .

\section{Lab values}

CBC

Hemoglobin: $13 \mathrm{~g} / \mathrm{dl}$

Hematocrit: $46 \%$

White Blood Cell: $6,000 / \mathrm{mm}^{3}$

Platelets: $200,000 / \mathrm{mm}^{3}$

Basic Metabolic Panel

Sodium: 125

Bicarbonate: 24

Potassium: 3.1

Chloride: 100

BUN: 45

Creatinine: $1.5 \mathrm{mg} / \mathrm{dL}$

Serum glucose: $60 \mathrm{mg} / \mathrm{dL}$

Point of care serum glucose: $60 \mathrm{mg} / \mathrm{dL}$

Serum cortisol level: $0.5 \mathrm{ug} / \mathrm{dl}$

TSH: $2.0 \mathrm{mIU} / \mathrm{L}$

Free T4: $1.2 \mathrm{ng} / \mathrm{dl}$

Urine drug screen

Opiates: negative

Barbiturates: negative

Methadone: negative

Amphetamines: negative

Cocaine: negative

Marijuana: negative

Urine analysis

pH: 5.0

Color: Clear dark yellow 


\section{Cureus}

Specific gravity 1.015

Ketones: none

RBCs: 2 RBC/hpf

WBC: $5 \mathrm{WBC} / \mathrm{hpf}$

Leukocyte esterase: negative

Nitrates: negative

Bacteria: none

Yeast: none

Bilirubin: negative

Blood cultures: No growth

\section{TABLE 6: Lab Values}

СBC: complete blood count; BUN: blood urea nitrogen; TSH: thyroid stimulating hormone; T3: triiodothyronine; T4: thyroxine; pH: potential of hydrogen; RBC/hpf: red blood cells per high-power field; WBC/hpf: white blood cells per high-powered field

Instructor Discussion Guide

I. Participants

II. Objectives

III. Role outline

\section{Debriefing}

Learner Evaluation

Review critical actions
Residents and upper-level medical students

Immediately address and treat acute symptoms of hypoglycemia and hypotension.

Identify signs and symptoms of adrenal insufficiency.

Obtain history of presenting illness, past medical history, and pharmacologic history.

Diagnose drug-induced adrenal crisis.

Treat adrenal insufficiency with appropriate steroids.

Recognize and treat adrenal insufficiency and adrenal crisis along with pertinent differential diagnoses.

Obtain appropriate history, discuss differential diagnoses and how to appropriately treat the patient with the learners, case summary.

Discussion with participants regarding their differential diagnoses.

Obtain bedside glucose. 


\section{Cureus}

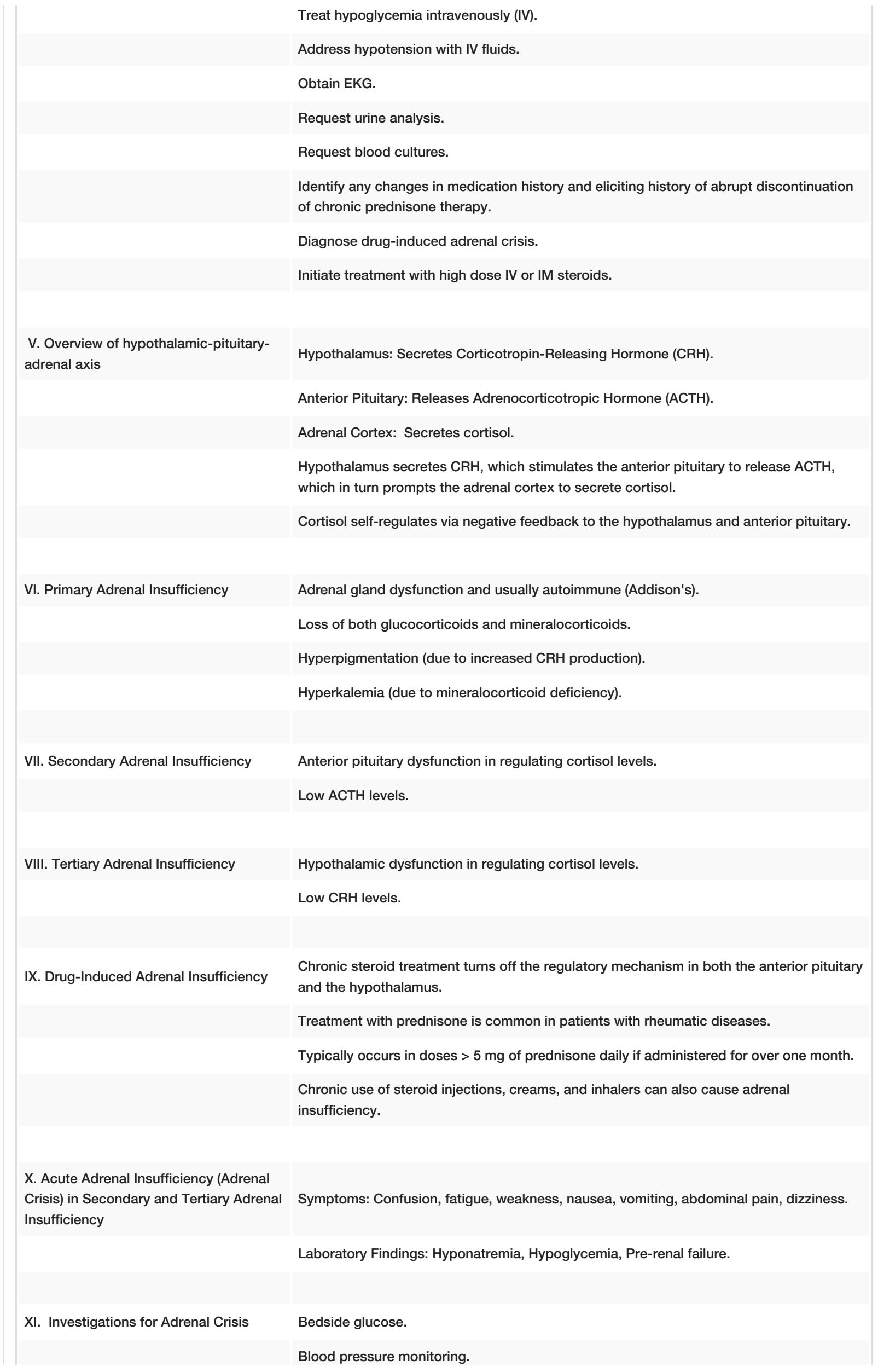




\section{Cureus}

\begin{tabular}{|c|c|}
\hline & EKG to exclude cardiac abnormality including myocardial infarction. \\
\hline & Test for infection with urinalysis and blood cultures. \\
\hline & Recent changes in medication history. \\
\hline & Blood counts and electrolyte counts. \\
\hline & TSH and free T4. \\
\hline & Cosyntropin test (Synacthen test or ACTH stimulation test). \\
\hline & $\begin{array}{l}\text { In primary adrenal insufficiency, aldosterone will be low due to additional loss of } \\
\text { mineralocorticoids. }\end{array}$ \\
\hline \multirow[t]{2}{*}{ XII. Cosyntropin test } & $\begin{array}{l}\text { Obtain baseline serum cortisol level, then administer ACTH and obtain repeat cortisol } \\
\text { level thirty minutes after administration of ACTH. }\end{array}$ \\
\hline & Do not need to wait for serum cortisol and ACTH levels to treat if the patient is unstable. \\
\hline \multirow[t]{9}{*}{ XIII. Differential Diagnoses } & Thyroid disorder, Myxedema Coma. \\
\hline & Hypoglycemia. \\
\hline & Diabetic Ketoacidosis. \\
\hline & Gastroenteritis. \\
\hline & Urinary tract infection. \\
\hline & Appendicitis. \\
\hline & Cholelithiasis. \\
\hline & Sepsis. \\
\hline & Adrenal insufficiency secondary to sarcoid granulomas. \\
\hline \multirow[t]{4}{*}{ XIV. Treatment } & Treatment of hypoglycemia with IV dextrose. \\
\hline & $\begin{array}{l}\text { Addressing hypotension with four to six liters of isotonic saline while frequently observing } \\
\text { for signs of fluid overload. }\end{array}$ \\
\hline & $\begin{array}{l}\text { Recommended doses of steroid therapy include } 100 \mathrm{mg} \text { hydrocortisone IV or IM as a } \\
\text { bolus dose followed by continuous intravenous administration of } 200 \mathrm{mg} \text { hydrocortisone } \\
\text { over a period of } 24 \text { hours. }\end{array}$ \\
\hline & $\begin{array}{l}\text { An alternate method includes pulse dosing of } 50 \mathrm{mg} \text { hydrocortisone IV or IM every six } \\
\text { hours }\end{array}$ \\
\hline \multirow[t]{3}{*}{$\mathrm{XV}$. Questions to stimulate discussion } & What are the differential diagnoses for adrenal insufficiency? \\
\hline & What did you use to make your final diagnosis of adrenal crisis? \\
\hline & $\begin{array}{l}\text { How would your treatment change if the patient also had an elevated white blood cell } \\
\text { count? }\end{array}$ \\
\hline
\end{tabular}

\section{TABLE 7: Instructor Discussion Guide}

EKG: electrocardiogram; IM: intramuscular: ACTH: adrenocorticotropic hormone; TSH: thyroid stimulating hormone; T4: thyroxine

Each learner completed the encounter once. On average, the learners took 10 to 15 minutes to complete the pre-scenario questionnaire. The actual standardized patient scenario lasted 10 minutes. The debriefing was completed in under 20 minutes and the post-scenario questionnaire (Table 5) took 10 to 15 minutes to 


\section{Cureus}

complete. Each case in its entirety concluded in less than one hour.

\section{Learner assessment}

We used five-point Likert scales for learner self-assessment, as well as learner evaluation of the module. We constructed an objective written test to determine baseline knowledge of adrenal insufficiency which was compared with a post-scenario test (Table 5). These diverse forms of assessment were used to create a comprehensive understanding of the utility of our module.

\section{Results}

Learners who completed the encounter included two third-year medical students (MS-III), two first-year residents (PGY-I), and two second-year residents (PGY-II). All except for one medical student had completed a simulation case or standardized patient scenario in the past. A five-point Likert scale was used in both pre- and post-assessment questionnaires. In the pre-assessment, when asked regarding their knowledge of six topics, on average, they considered themselves to have the least knowledge of adrenal insufficiency, thyroid storm, and sarcoidosis (Figure 1).

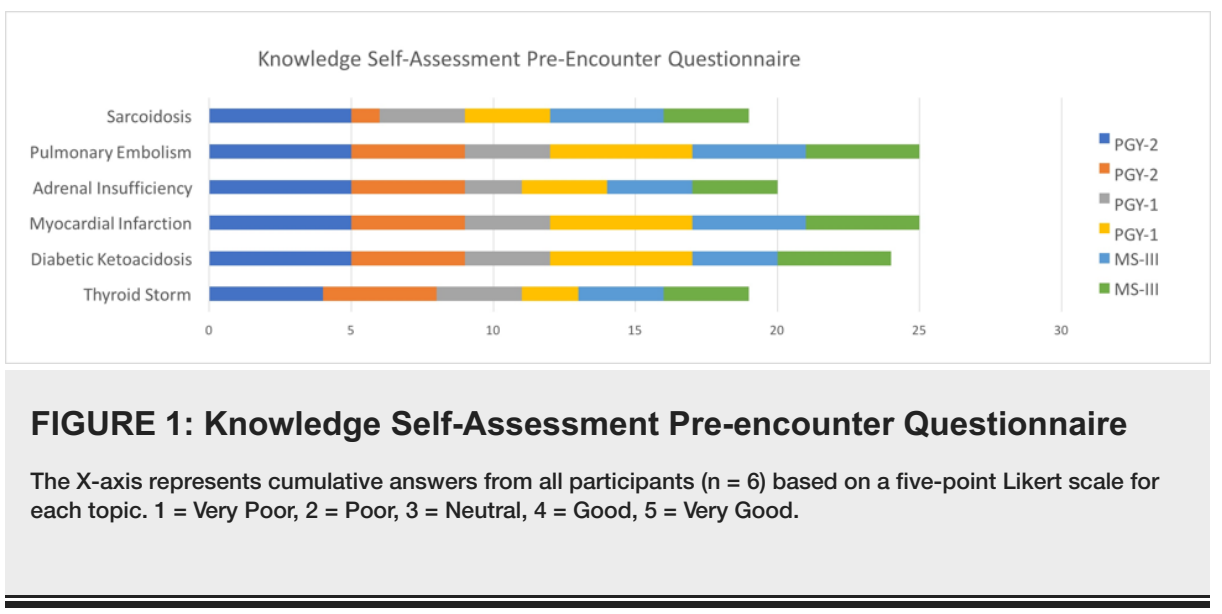

To assess objective medical knowledge of adrenal insufficiency and thyroid disorder, the learners completed eight pre-encounter questions for each topic. The average score of the adrenal insufficiency test was 5.33 out of 8 (66.63\% correct), and no learner answered more than six out of eight questions correctly. The average score of the thyroid disorder test was 7.33 out of 8 (91.25\% correct), and all learners answered at least six out of eight questions correctly (Figure 2).

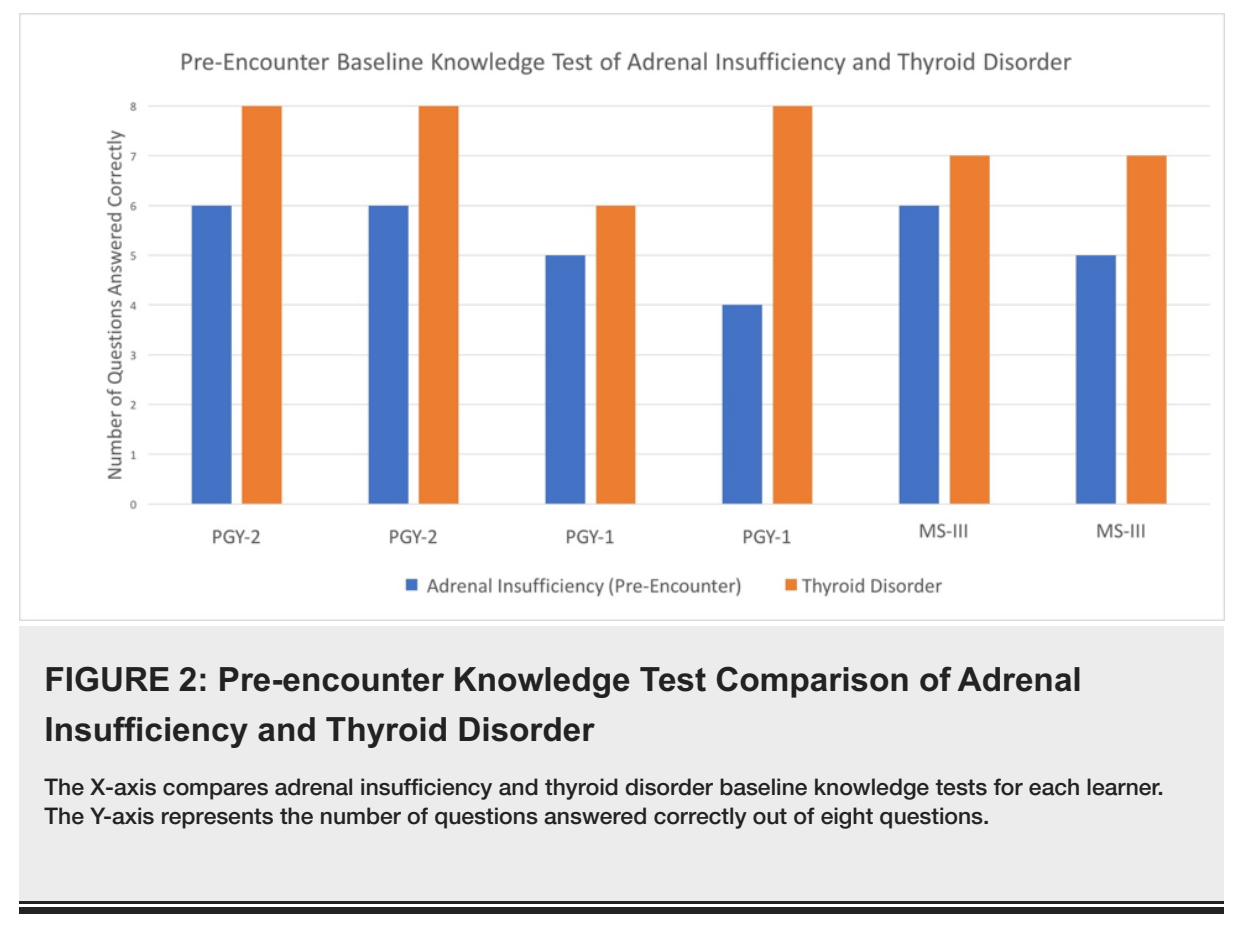

In the post-encounter questionnaire, all learners found that the simulation case contributed to their understanding of adrenal insufficiency and that the simulation case was well-devised to achieve this goal 


\section{Cureus}

(Figure 3). Learner self-assessment of their own knowledge and comprehension of sarcoidosis and adrenal insufficiency improved post-encounter.

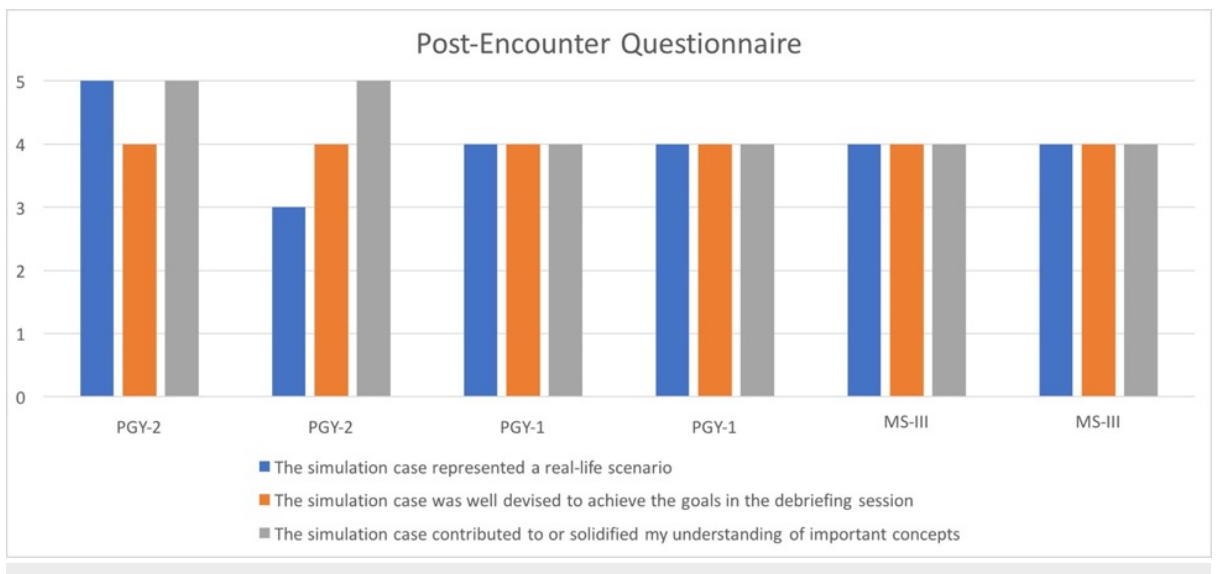

\section{FIGURE 3: Post-encounter Questionnaire}

X-axis represents five-point Likert scale. $1=$ Strongly Disagree, $2=$ Disagree, $3=$ Neutral, $4=$ Agree, $5=$ Strongly agree

When asked regarding their self-assessment of knowledge and comprehension of adrenal insufficiency and sarcoidosis post-encounter and debriefing, overall, the learners' reported that their knowledge and comprehension had improved in comparison to the pre-assessment (Figure 4).

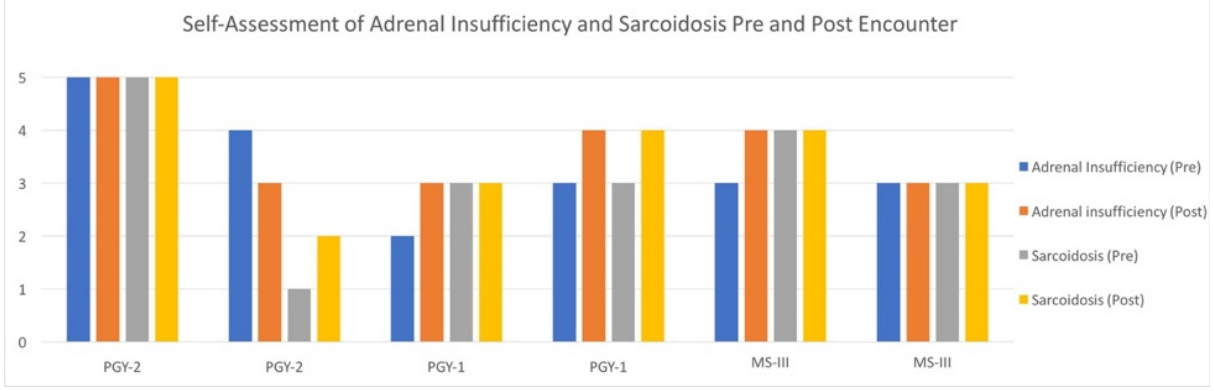

FIGURE 4: Pre and Post Encounter Self-Assessment Questionnaire.

Self-assessment of knowledge and comprehension of adrenal insufficiency and sarcoidosis. The Y-axis represents a five-point Likert scale. 1= Very Poor, 2=Poor, 3= Neutral, 4= Good, 5=Very Good.

After completing the encounter and debriefing, the learners were asked the same eight pre-encounter questions to re-assess medical knowledge of adrenal insufficiency. The mean score on the adrenal insufficiency knowledge test went up from an average of $66.63 \%$ to $87.50 \%$ correct (Figure 5).

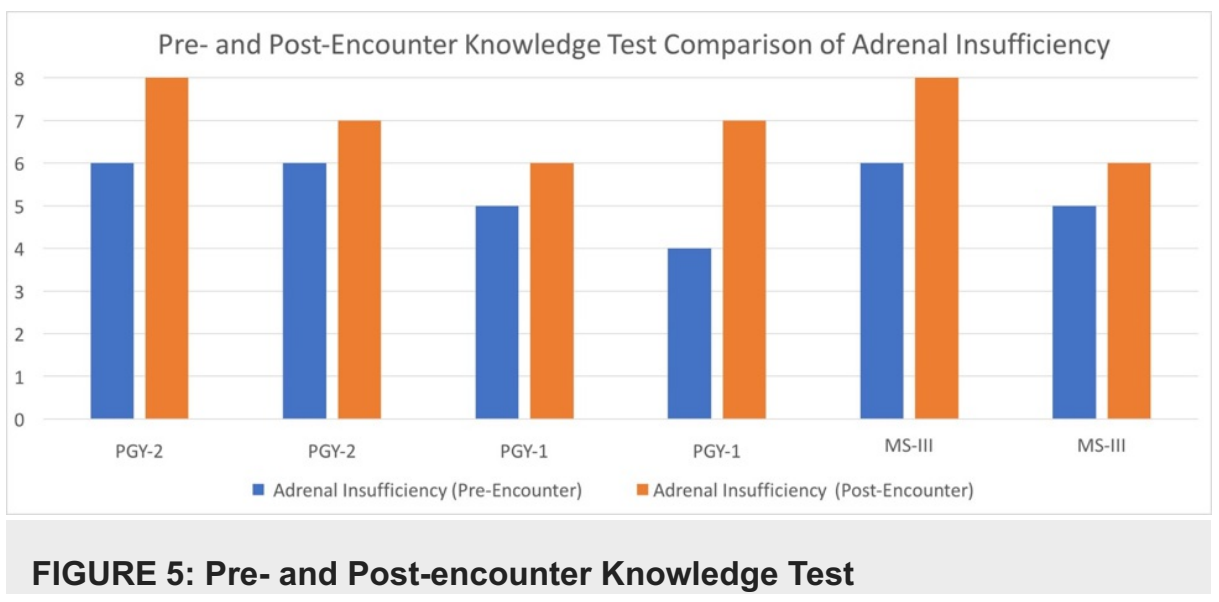




\section{Discussion}

In the pre-assessment, we asked the learners whether they had more knowledge of thyroid disease or adrenal insufficiency, and they were more confident in their knowledge of adrenal insufficiency. It was interesting to note that there was a discrepancy between the self-assessment and objective assessment. In the preassessment, learners overall answered $91.25 \%$ of questions correctly regarding thyroid disorder, but only $66.63 \%$ of adrenal insufficiency questions were answered correctly. The learners were initially overconfident in adrenal insufficiency and less than confident in thyroid disorder despite objective tests of medical knowledge indicating that they were less knowledgeable in adrenal insufficiency and had good knowledge of thyroid disorder.

During the debriefing session, the learners indicated that they were surprised that they were not able to diagnose adrenal insufficiency quickly from the onset of the simulation. We discussed the classification of primary, secondary, tertiary, and acute adrenal insufficiency, and how to differentiate them clinically. Defining types of adrenal insufficiency unexpectedly became the main focus due to extensive questions from the participants. There was less discussion regarding treatment of adrenal insufficiency. During our debriefing, the learners indicated they were more comfortable with initiating treatment with steroid therapy than they were in making the diagnosis.

Overall, the first-year internal medicine residents had the least knowledge of adrenal insufficiency and improved the most on our objective tests. This unexpected finding may be due to the third-year medical students having recently completed a knowledge-based medical board examination. Another possible explanation is the flexibility of fourth-year medical school resulting in variations in baseline knowledge in the months prior to starting residency training. As a result of these findings, this module may be best suited for first-year residents in internal medicine, emergency medicine, or family medicine, and upper-level medical students. Alternatively, it could be used for upper-level residents who may require remediation. Our case can be utilized alongside a MedEd adrenal insufficiency workshop to solidify basic science concepts [8].

A challenge to this approach is in representing a real-life scenario during the enactment of the scene. In hospitals that do not have standardized patients or simulation centers, it is important to fully prepare and guide the individual who will be performing as the patient in the scenario. For the sake of realism, the individual should develop a familiarity with the script, as well as rehearse the scenario prior to enacting the simulation with the learners. As noted previously, we incidentally found a similar simulation scenario published in MedEd from 2015 in which a patient with sarcoidosis presents with adrenal crisis [7]. It is reasonable to consider that sarcoidosis predisposes patients to adrenal insufficiency in ways that we had not originally anticipated. Further investigations of hospitalized patients with adrenal insufficiency may determine whether sarcoidosis is correlated with an increased incidence of adrenal insufficiency than in other disease processes when chronic steroids are abruptly discontinued.

\section{Conclusions}

Overall, feedback from our residents as determined in a five-point Likert scale, as well as objective tests of knowledge, showed we were able to improve knowledge and comprehension of adrenal insufficiency within a short period of time using a learner-based scenario. The success of our simulation in developing participants' medical knowledge adds to current evidence showing that using simulation scenarios as an adjunct to teaching improves education and enhances comprehension.

\section{Additional Information}

\section{Disclosures}

Human subjects: All authors have confirmed that this study did not involve human participants or tissue. Animal subjects: All authors have confirmed that this study did not involve animal subjects or tissue. Conflicts of interest: In compliance with the ICMJE uniform disclosure form, all authors declare the following: Payment/services info: All authors have declared that no financial support was received from any organization for the submitted work. Financial relationships: All authors have declared that they have no financial relationships at present or within the previous three years with any organizations that might have an interest in the submitted work. Other relationships: All authors have declared that there are no other relationships or activities that could appear to have influenced the submitted work.

\section{References}

1. Bancos I, Hahner S, Tomlinson J, Arlt W: Diagnosis and management of adrenal insufficiency . Lancet Diabetes Endocrinol. 2015, 3:216-26. 10.1016/S2213-8587(14)70142-1 


\section{Cureus}

2. Chakravarthy MV: Adrenal Insufficiency. Endocrinology Subspecialty Consult, 2nd Edition. Henderson KE, Baranski TJ, Bickel PE, Clutter WE, McGill JB (ed): Wolters Kluwer, St. Louis; 2008. 70-79.

3. Herman JP, McKlveen JM, Ghosal S, Kopp B: Regulation of the hypothalamic-pituitary-adrenocortical stress response. Compr Physiol. 2016, 6:603-21. 10.1002/cphy.c150015

4. Nelson DL, Cox MM: Hormonal Regulation of Fuel Metabolism. Lehninger Principles of Biochemistry, 5th edition. Nelson DL, Cox MM (ed): W H Freeman \& Company, New York; 2008. 922-29.

5. Arlt W: Society for Endocrinology Endocrine Emergency Guidance: emergency management of acute adrenal insufficiency (adrenal crisis) in adult patients. Endocr Connect. 2016, 5:G1-G3. 10.1530/EC-16-0054

6. Fraser K, Wright B, Girard L, et al.: Simulation training improves diagnostic performance on a real patient with similar clinical findings. Chest. 2011, 139:376-81. 10.1378/chest.10-1107

7. Kulkarni M, Warren K: Adrenal crisis simulation. MedEdPORTAL. 2015, 11:10248. 10.15766/mep_23748265.10248

8. Litvin J: Clinical correlation workshop using a team approach to learning: adrenal insufficiency . MedEdPORTAL. 2013, 9:9350. 10.15766/mep 2374-8265.9350 